\section{Intervenção psicoeducacional nos transtornos do humor: a experiência do Grupo de Estudos de Doenças Afetivas (GRUDA)}

\section{Sr. Editor,}

A eficácia da farmacoterapia do transtorno bipolar já está bem documentada. Entretanto, fatores psicossociais contribuem em 25 a 30\% das alterações no curso da doença, ${ }^{1}$ influenciando a recuperação social e funcional e comprometendo sua qualidade de vida. Entre as abordagens psicológicas estudadas, a intervenção psicoeducacional foi a que encontrou maior suporte de estudos controlados..$^{2-3}$ Os estudos realizados, porém, utilizam grupos fechados de pacientes e não há estudos sobre a eficácia desta intervenção quando ela é oferecida a grupos abertos, com maior número de participantes e, portanto, mais adequados à realidade brasileira. Iniciamos o estudo e a implantação de intervenções psicoeducacionais em 1997. ${ }^{4} \mathrm{Em}$ função da demanda por intervenções psicológicas integradas ao tratamento farmacológico, em 2002, as intervenções psicoeducacionais foram reestruturadas para o formato de encontros abertos, abrangendo, assim, maior número de pessoas. Os temas abordados foram escolhidos através de pesquisa acerca das principais dúvidas sobre o transtorno. Realizamos 10 encontros, com o seguinte formato: $30 \mathrm{mi}-$ nutos para a exposição do tema, 30 minutos para depoimentos e 1 hora para a discussão geral. Cada encontro reuniu, em média, 80 participantes novos, totalizando, aproximadamente, 800 participantes ao ano. Mais da metade (60\%) retornou aos demais encontros, favorecendo a constância da maioria do grupo e indicando, de maneira indireta, os efeitos positivos alcançados.

A utilização de encontros psicoeducacionais em grupos abertos é uma experiência inédita e na literatura nacional não encontramos outros trabalhos. A medida de efetividade deste tipo de intervenção ainda precisa ser estabelecida. Por isso, os resultados encontrados são pouco objetivos, mas as conclusões tiradas podem ser assim resumidas: 1) os depoimentos e a discussão geral foram especialmente importantes para o caráter psicoeducativo desta intervenção; 2) as trocas de experiências estimularam a aquisição de habilidades em prevenir recorrências ou prejuízos psicossociais acarretados pela doença; 3) a linguagem clara e objetiva das palestras esclareceu dúvidas quanto ao caráter crônico da doença e o tratamento, diminuindo preconceitos e favorecendo a aderência. A organização dos encontros deve ser feita por uma equipe multiprofissional (psiquiatras, psicólogos e outros profissionais), coesa e treinada para lidar com grupos grandes de pessoas. A troca espontânea de experiências deve ser incentivada e, para isso, é importante criar, por um lado, um ambiente não crítico e sim de aceitação e, por outro, o estabelecimento de limites claros que restrinjam inadequações (freqüentes, em se tratando de bipolares nem sempre estáveis), principalmente com relação ao tempo utilizado e natureza da colocação pessoal.

A principal conclusão deste trabalho é que, além dos benefícios já conhecidos de intervenções psicoeducacionais associadas ao tratamento de bipolares, é possível adequar esta abordagem a grupos grandes e abertos que incluam pacientes, familiares e interessados no tema. Apesar da falta de medidas de avaliação para este tipo de experiência, este é, sem dúvida, um método de fácil aplicação, de baixo custo e de ampla abrangência, e deveria ser mais estimulado, particularmente em centros de assistência pública aonde o acesso a intervenções psicológicas individuais ou de grupo são mais difíceis.

\section{Mireia C Roso, Ricardo A Moreno, Elisabeth M Sene Costa} Grupo de Estudos de Doenças Afetivas Instituto de Psiquiatria do Hospital das Clínicas da Faculdade de Medicina da Universidade de São Paulo

Financiamento: Inexistente

Conflito de interesses: Inexistente

\section{Referências}

1. Bauer MS, Kirk GF, Gavin C, Williford WO. Determinants of funcional outcome and healthcare costs in bipolar disorder: a high-intensity follow up study. J Affect Disord. 2001;65(3):231-41.

2. Colom F, Vieta E. A perspective on the use of psychoeducation, cognitive-behavioral therapy and interpersonal therapy for bipolar patients. Bipolar Disord. 2004;6(6):480-6.

3. Jones S. Psychotherapy of bipolar disorder: a review. J Affect Disord. 2004;80(2-3):101-14.

4. Moreno RA, Andrade ACF. A psychoeducational approach in treatment of bipolar patients [abstracts]. In: $2^{\circ}$ International Conference on Bipolar Disorder. Pittsburgh, Pennsylvania: 19-21 june 1997.

\section{Freqüência de epilepsia em pacientes psiquiátricos internados}

\section{Sr. Editor,}

Epilepsia é um transtorno neurológico comum com uma prevalência pontual na população geral entre 0,5 e $1 \%$ e uma taxa de prevalência ao longo da vida entre 1,5 e $5 \%{ }^{1}{ }^{1} \mathrm{~A}$ comorbidade com transtornos psiquiátricos é elevada, encontrando-se entre $22 \%$ e $58 \%$ em crianças e entre 19 e $52 \%$ em adultos com epilepsia. ${ }^{2}$

O estudo de Marchetti et al, apresentado no XXII Congresso Brasileiro de Psiquiatria, em Salvador, ${ }^{3}$ e também publicado nessa secção, ${ }^{4}$ revelou dados interessantes sobre inquérito realizado no congresso anterior sobre "Atitudes de psiquiatras brasileiros em relação à epilepsia". De 157 psiquiatras entrevistados, $95 \%$ referiram já ter tratado pacientes com epilepsia e algum tipo de transtorno mental. Destes, $80 \%$ relataram insatisfação com o nível de informação pessoal sobre o tema epilepsia e $98 \%$ desejavam maior conhecimento a respeito. ${ }^{3-4}$

Motivados por esse trabalho, realizamos revisão de prontuário de 119 pacientes internados (M/F, 59/60) no hospital psiquiátrico Instituto Raul Soares, em Belo Horizonte, em maio de 2004. Avaliamos a freqüência de epilepsia, definida a partir da história clínica e da descrição no prontuário de crises epilépticas recorrentes na ausência de condições tóxico-metabólicas, algumas características sociodemográficas, os diagnósticos psiquiátricos associados e o tempo de internação.

A freqüência de epilepsia na amostra estudada foi de 10,1\% 